Colloque C2, suppl. au Journal de Physique II, Vol. 1, septembre 1991

\title{
INFLUENCE OF EXCITATION FREQUENCY ON ORIENTED (1010) GROWTH OF ALUMINIUM NITRIDE THIN FILMS BY PECVD
}

\author{
N. AZEMA* , J. DURAND*, R. BERJOAN**, J.L. BALLADORE*** and \\ L. $\mathrm{COT}^{*}$ \\ *Laboratoire de Physicochimie des Matériaux, URA 1312 du CNRS, \\ 8 rue de 1 'École Normale, F-34053 Montpellier cedex 1, France \\ ** Institut de science et de Génie des Matériaux et Procédés. \\ $B P$ 5, Odeillo, F-66120 Font Romeu, France \\ **" CEMES-LOE CNRS, 29 rue Jeanne-Marvig, F-31055 Toulouse, \\ France \\ - ABSTRACT:
}

The Metal-Organic Chemical Vapor Deposition process assisted by reactive plasma, leads to AlN coatings with oriented (1010) structure. The Aluminium nitride was synthesized on a wide range of substrates (Silicon (100) or (111) wafers, graphite, polycrystalline Silicon Carbide and glass plates) from trimethylaluminium and ammonia at $330^{\circ} \mathrm{C}$. The a-axis orientation of AlN coatings, which does not depend on the substrate, changes with the excitation frequency. Material crystallinity and elementary composition were examined mainly by $\mathrm{X}$-ray diffraction and Auger Electron Spectroscopy respectively. Crystalline AlN was obtained for low frequency fields $(35-110-440 \mathrm{kHz})$ with mean crystallite sizes of $200-600 \AA$, whereas amorphous films were obtained using a $13.56 \mathrm{MHz}$ frequency. The AES analysis has revealed compositions similar to AlN with a small percentage of Carbon (2-4 \%) and no Oxygen (for all experimental conditions). To corroborate these results, Scanning Transmission Electron Microscopy and Infra-Red absorption spectroscopy are used.

\section{I - INTRODUCTION :}

In recent years, a wide range of applications has been found for AlN in microelectronic/1/, optic/2/, Surface Acoustic Wave (SAW) techniques/3/... This paper deals with growth of Aluminium nitride as well as coating material.

AlN thin coatings have been studied as single crystal epitaxial films $/ 4$ / or polycrystalline structures $/ 5 /$. A c-axis orientation is observed depending on the experimental process. There are several growth methods of this crystalline ceramic such as Chemical Vapor Deposition (CVD) process, reactive Molecular Beam Epitaxy, reactive RF sputtering. In all these cases the growing temperatures are upper $800-1200^{\circ} \mathrm{C}$.

Hasegawa and al./6/ have shown that amorphous AlN thin layers can be deposited at $300^{\circ} \mathrm{C}$ by Metal-Organic Plasma Enhanced Chemical Vapor Deposition (MOPECVD).

Recently, the growth of polycrystalline AIN with a (0001) preferred orientation has been accomplished at a substrate temperature of $550^{\circ} \mathrm{C}$ by a coaxial-line-type Microwave Plasma Chemical Vapor Deposition process $/ 7 /$.

In the present work, MOCVD assisted by reactive plasma allows the preparation at $330^{\circ} \mathrm{C}$ of AlN coatings, with a (10i0) orientation, on a wide range of substrates. The influences of excitation frequency and of substrates kind were studied. The material crystallinity and elementary composition were examined respectively by $\mathrm{X}$-ray diffraction and Auger Electron Spectroscopy, with complementary studies by Infra-Red absorption spectroscopy. On the other hand, Transmission Electron Microscopy (TEM) observations revealed the film-substrate interface and showed the AlN crystallites.

\section{2 - EXPERIMENT :}

\section{1 - Deposition system :}

The schematic arrangement, synthesis conditions $\left(\mathrm{P}=7 \mathrm{~Pa}, \mathrm{~W}=0.26 \mathrm{~W} \mathrm{~cm}^{-2}\right)$ and precursor utilization (TMA, $\mathrm{NH}_{3}, \mathrm{~N}_{2}$ ) have been described in a previous work $/ 8 /$.

Four different generators capacitively coupled to the system were used to supply RF power of $50 \mathrm{~W}$. Thereby three different low-frequency fields ( $35 \mathrm{kHz}, 110 \mathrm{kHz}$ and $440 \mathrm{kHz}$, respectively Addax, Plasmatek and Celes) and a 
high frequency one $(13,56 \mathrm{MHz}$, Plasma-Therm Inc.) could be used to synthesize crystallized or amorphous AlN films. The substrate temperature was always kept at $330^{\circ} \mathrm{C}$.

From this reactive system, AlN films were successfully obtained in all these plasma atmospheres.

\section{2 - Film characteristics :}

- SEM :

Scanning electron micrographs (figure 1) show uniform, dense AlN coatings with an excellent adherence to the substrate and a very good step coverage. These results are independent of the excitation frequency choice and of the substrates material (polished Silicon wafers, graphite substrate or polycrystalline sintered Silicon Carbide). The surface shows a low defect density.

\section{- ELLIPSOMETRY :}

The refractive index of the film deposited on (100) Silicon wafer was measured at $30^{\circ}$ incidence angle $/ 9 /$ by a Plasmos SD2300 ellipsometer on Silicon wafer substrates. The $n$ values vary between 2.0 and 2.2 with a $6328 \AA$ wavelength in good agreement with the literature $/ 10 /(n=2.17)$.

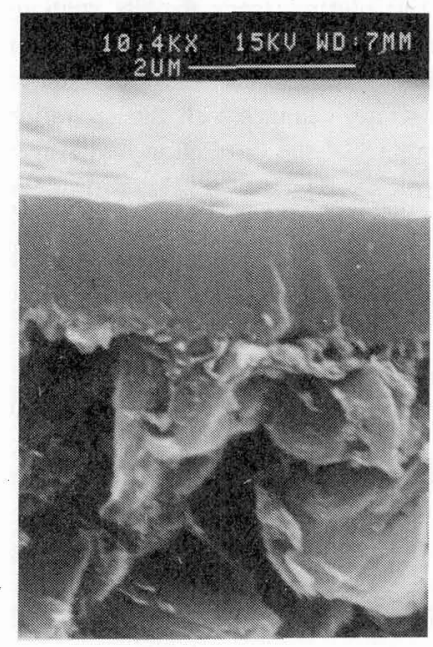

Fig. 1 : AlN coating on grapinite substrate.

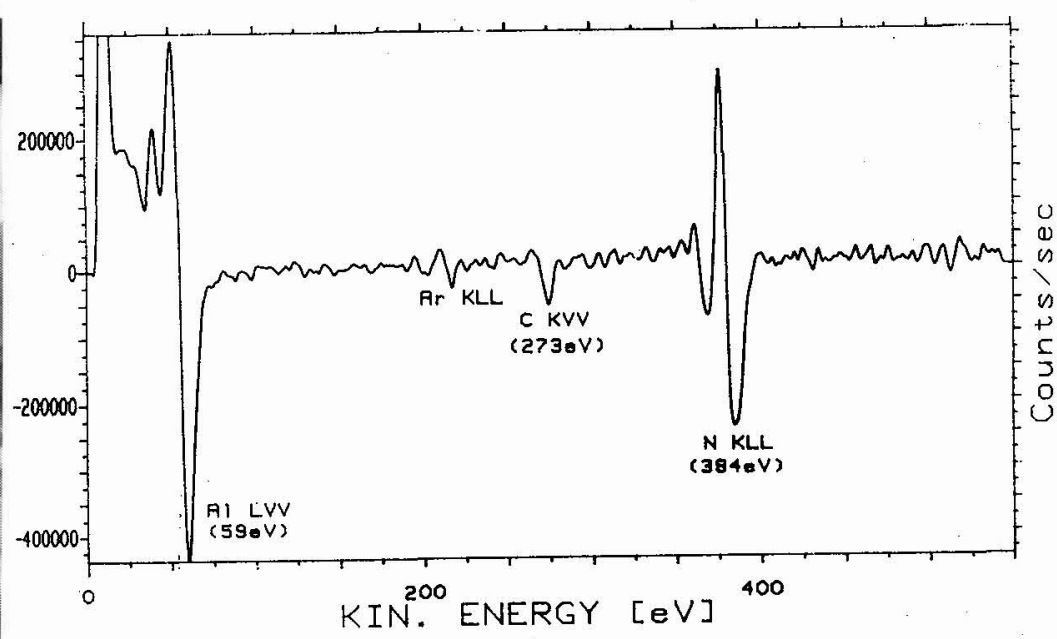

Fig. 2 : Auger electron energies spectra of AlN.

\section{- IR ABSORPTION :}

IR spectra of AlN deposited on (100) Silicon wafers were carried out with a Nicolet Fourier Transform InfraRed (FTIR) spectrometer (model 5ZDX) in the $400-4000 \mathrm{~cm}^{-1}$ wave-numbers range. All the spectra show a broad single strong peak at $670 \mathrm{~cm}^{-1}$ associated to the stretching Al-N vibrating group. Two other absorption-band areas have also been identified in previous works $/ 8 /:$ N-H $\left(3205 \mathrm{~cm}^{-1}\right)$ and Al-H $\left(2108 \mathrm{~cm}^{-1}\right)$. The Hydrogen source in the film was ammonia or TMA reactants.

- AES :

The samples Auger electrons were analysed by a Riber Mac-2 Auger spectrometer (analyser resolution is 1 eV). Parameters such as the primary beam electron energy and the gun electron emission current were kept constant. After a primary cleaning of the surface, the AES data are scanned while keeping ionic sputtering with a Riber CI 50 ion gun. The shift due to the charge effects for insulator materials and adsorbed surface contaminants (Oxygen and Carbon) were avoided by a surface cleaning. 
In this way, the plasma deposits reveal few impurities : a small percentage of Carbon (2-4\%) and no Oxygen is detected $(<<1 \%)$, as shown in figure 2 .

\section{3 - INFLUENCE OF THE EXCITATION FREOUENCY:}

\section{1 - Deposition kinetics:}

We have mentioned that in this work the situations in PECVD reactor differ only by the discharge frequency. First, the dependence on the deposition rate is studied in figure 3 for the three frequencies : $35-440 \mathrm{kHz}$ and 13.56 $\mathrm{MHz}$. The deposition rate decreases when the frequency value increases. Those differences mainly account for the ionic bombardment effects during the film growth (flux and energy of the positive incident ions) when the excitation frequency varies. This may cause changes in the growth kinetic, stucture, composition and stresses in the film. The higher ionic bombardment (with more energetic species at low frequency) favours an important number of adsorption sites/11/ and therefore increases the deposition rate.

Later on, we will study the structure variation and verify by AES, to know whether the composition is disturbed by frequency changes.

INFLUENCE OF THE EXCITATION FREQUENCY

ON THE DEPOSITION RATE

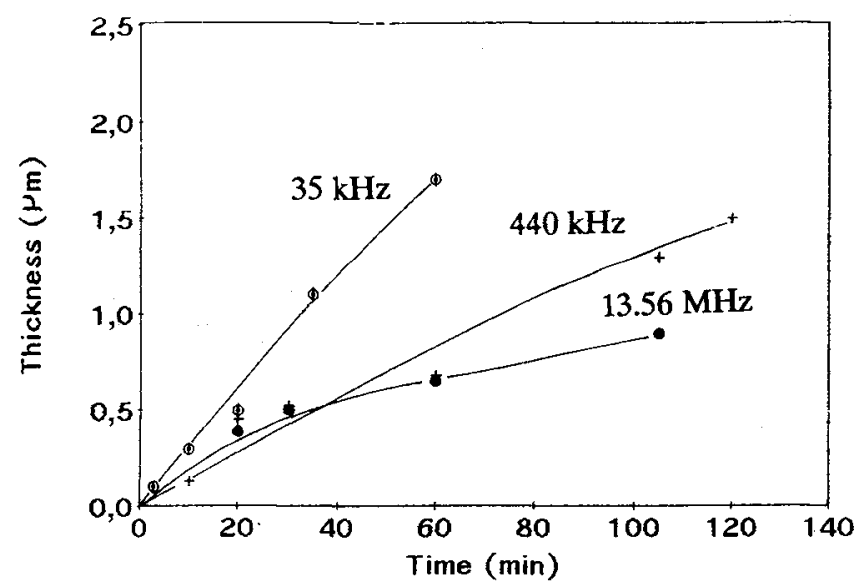

Fig. 3 : Deposition kinetics for different frequencies.

\section{2 - X-Ray measurements :}

\subsection{1 - Frequency influence on the crystallite size.}

We use a Curved Position Sensitive Detector for X-ray diffraction. In figure 4 significant differences in film crystallinity produced with high and low frequency RF excitations are observed when all the other parameters are the same. For the 35-110-440 kHz frequencies, the films diffraction patterns indicate a strong preferential orientation of the microcrystallites along the (1010) direction (ASTM data card n²5-1134). Only for the $13.56 \mathrm{MHz}$ frequency no peak are present. AIN thin films are amorphous under these last synthesis conditions, which is in good agreement with the Hasegawa's works $/ 6 /$.

Furthermore, the mean crystallite grain size is investigated, L (in Angstroms), from the measurement of the additional broadening due to small particles size $(<2000 \AA)$. The commonly accepted formula is the Scherrer formula/12/:

$$
\mathrm{L}=(0.9 \lambda) /\left(\mathrm{B} \cos \theta_{\mathrm{B}}\right)
$$

where $\lambda$ is the $\mathrm{X}$-ray wavelength (Cu $\mathrm{K}_{\alpha 1}$ radiation : $\lambda=1.54183 \AA$ ), $\theta_{\mathrm{B}}$ the Bragg angle, and $\mathrm{B}$ the line broadening 
obtained from the Warren formula/12/:

$$
\mathrm{B}^{2}=\mathrm{B}_{\mathrm{M}^{2}-\mathrm{B}^{2}}
$$

where $B_{M}$ and $B_{S}$ are the full width half maximum (FWHM) for the film and the standard sample respectively. The (104) line (ASTM data card $\mathrm{n}^{\circ}$ 10-173) of $\alpha$ alumina powder (PECHINEY Gardanne) with a granulometry of $5.6 \mu \mathrm{m}$ was choosed as a standard peak.

The crystallite size is similar for the $35 \mathrm{kHz}$ and $110 \mathrm{kHz}$ frequencies (with a 500-600 $\AA$ range) ; these values decrease until $260 \AA$ at $440 \mathrm{kHz}$. In opposition to $A$. Matsuda/13/, an increase in the ions energy (low frequency) induces a decrease in crystallites size. The thin film becomes amorphous at $13.56 \mathrm{MHz}$ (low ionic energy). For a given frequency, the crystallite dimensions are the same even though the coating thickness changes.
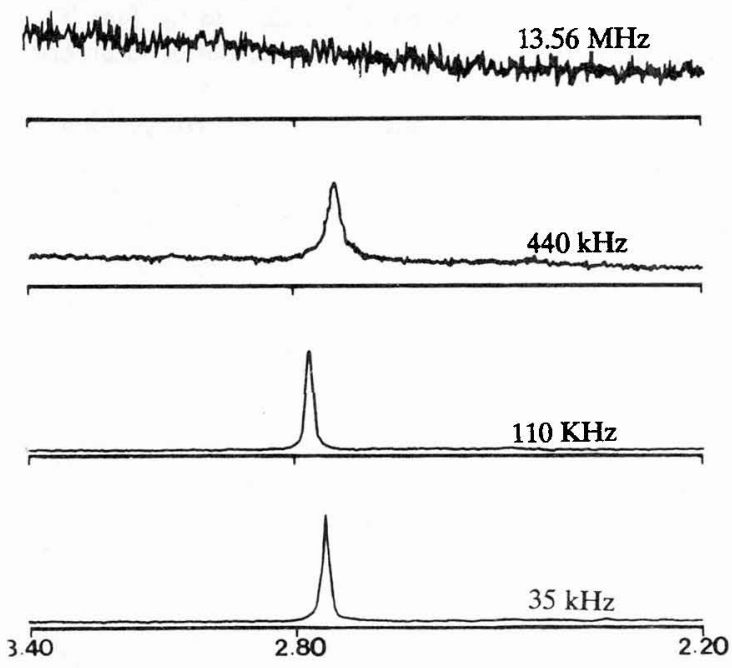

Fig. 4 : Influence of the excitation frequency on the film crystallinity.
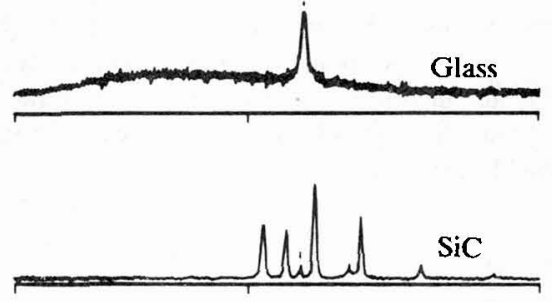

Si (111)

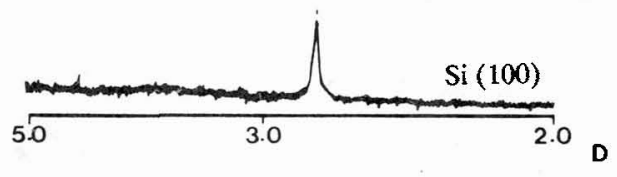

Fig. 5 : Influence of the substrate on AlN crystalline orientation.

Table 1: Mean values of crystallite sizes (L).

\begin{tabular}{|c|c|c|c|c|}
\hline $\begin{array}{l}\text { Samples } \\
\text { (thickness) } \\
(\mu \mathrm{m})\end{array}$ & $\theta_{\mathbf{B}}\left({ }^{\circ}\right)$ & $\mathbf{B}_{\mathbf{S}}$ or $\mathbf{B}_{\mathbf{M}}\left(^{\circ}\right)$ & B $(\AA)$ & $\begin{array}{l}\mathbf{L}(\AA) \\
(+/-50 \AA)\end{array}$ \\
\hline $\begin{array}{l}\text { Alumina } \\
(5.6)\end{array}$ & 17.45 & $\mathrm{~B}_{S}=0.14$ & - & $\begin{array}{l}\text { granulometry= } \\
5.6 \mu \mathrm{m}\end{array}$ \\
\hline $\begin{array}{l}\text { AlN-35kHz } \\
(0.5)\end{array}$ & 16.24 & $\mathrm{~B}_{\mathrm{M}}=0.21$ & $B=0.16$ & 530 \\
\hline $\begin{array}{l}\text { AlN-35kHz } \\
\text { (1.2) }\end{array}$ & 16.32 & $\mathrm{~B}_{\mathrm{M}}=0.20$ & $B=0.14$ & 580 \\
\hline $\begin{array}{l}\text { AlN-35kHz } \\
\text { (1.73) }\end{array}$ & 16.40 & $\mathrm{~B}_{\mathrm{M}}=0.22$ & $B=0.17$ & 490 \\
\hline AlN-110kHz & 16.13 & $\mathrm{~B}_{\mathrm{M}}=0.21$ & $B=0.16$ & 500 \\
\hline AlN-440kHz & 16.31 & $\mathbf{B}_{\mathbf{M}}=0.33$ & $B=0.30$ & 260 \\
\hline
\end{tabular}




\subsection{2 - Effect of the substrate :}

A similar study investigated influences of both substrate crystalline orientation and surface roughness. In the figure 5, AlN is deposited on polished Silicon wafers with two different crystalline orientations ( $\mathrm{Si} \mathrm{(100)}$ and Si (111)) : no impact is observed. The same behaviours are shown on other crystallized substrates with more important roughness surface (sintered Silicon Carbide) and on amorphous glass plates. As it will be confirmed by crystallite size measurements (in table 2) and by TEM micrographs (figure 8), the type of substrates (crystallinity and roughness) has no consequential effects on the coating crystallinity.

Table 2: AlN synthesized at $440 \mathrm{kHz}$ for two experiments.

\begin{tabular}{|c|c|c|c|c|}
\hline Substrates & $\theta_{\mathbf{B}}\left(^{\circ}\right)$ & $\mathbf{B}_{\mathbf{M}}\left(^{\circ}\right)$ & $\mathbf{B}\left({ }^{\circ}\right)$ & $\begin{array}{l}L(\AA) \\
(+/-50 \AA)\end{array}$ \\
\hline \multicolumn{5}{|c|}{ Experiment 1: } \\
\hline glass plate & 16.33 & 0.32 & 0.29 & 280 \\
\hline Silicon(100) & 16.32 & 0.33 & 0.30 & 270 \\
\hline \multicolumn{5}{|c|}{ Experiment 2: } \\
\hline$\alpha$ Alumina & 16.52 & 0.40 & 0.38 & 220 \\
\hline Silicon(100) & 16.53 & 0.34 & 0.31 & 260 \\
\hline
\end{tabular}

\section{3 - IR and TEM :}

\subsection{1 - Infra-Red absorption measurements :}

Figure 6 shows the broadening of Al-N band at a $13.56 \mathrm{MHz}$ frequency which represents the amorphous AlN films with regard to the three others. This is in good agreement with the X-ray data.

An amount of Hydrogen can be trapped in the growing films. It is bonded to Aluminium or Nitrogen atoms. Figure 7 shows the beight peak with respect to the coating thickness. A maximum quantity of hydrogen, bonded to Aluminium atoms, seems to exist for the amorphous samples. It may act an important part in the AlN amorphous state.

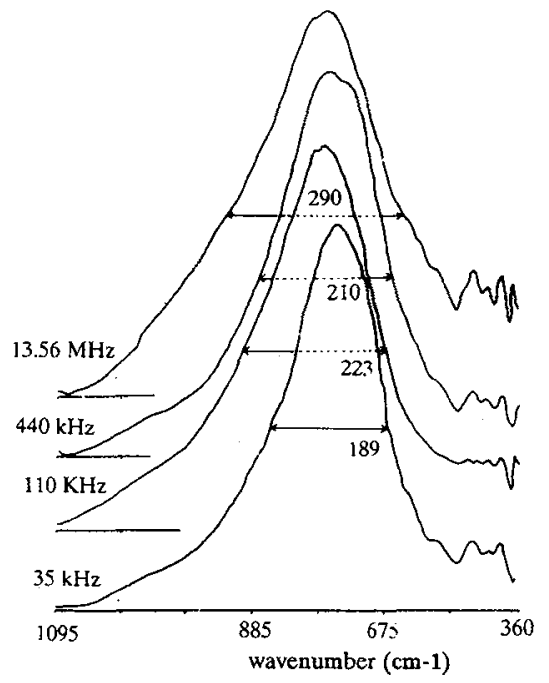

Fig. 6 : Broadening of Al-N vibrating bond. 


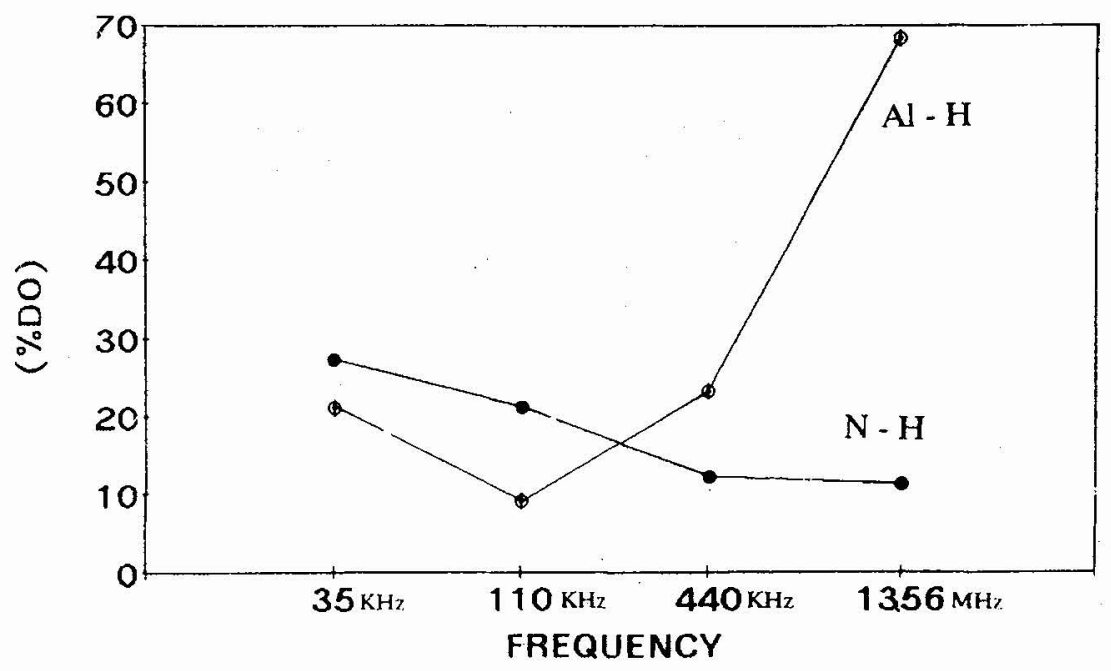

Fig. 7 : Intensities of Al-H and N-H bond observed in IR.

\subsection{2 - TEM observations :}

Sample preparations have been made by the cross section method/14/ and observed on a Jeol $200 \mathrm{CX}-\mathrm{T}$. The micrographs (figure 8) reveals AlN crystallites with a perpendicular orientation to the (100) Silicon direction.

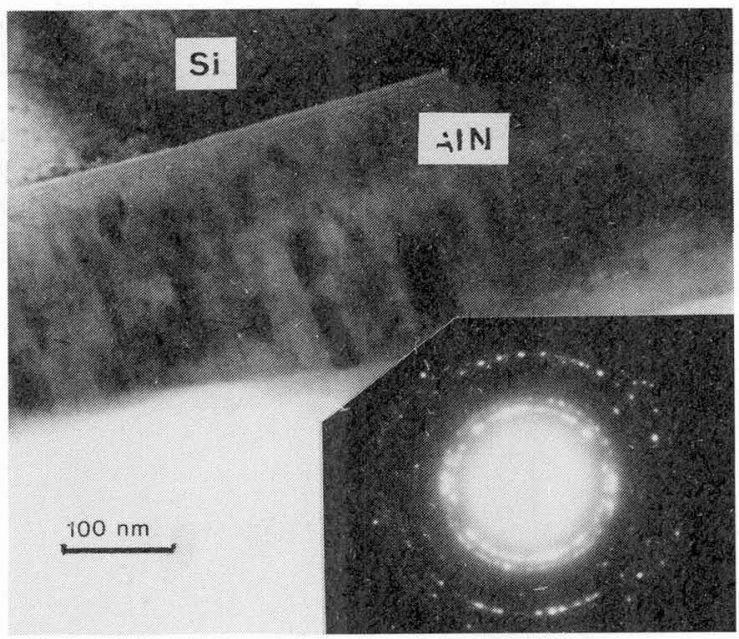

Fig. 8 : Bright field image of cross section with diffraction pattern of the AlN domain.

\section{4 - AES analysis :}

We were interested in the evaluation of molecular concentrations in the $\mathrm{Al}_{\mathbf{x}} \mathrm{N}_{\mathbf{y}}$ films. They have been obtained from the E.N(E) Auger spectra scanned in the $50-520 \mathrm{eV}$ range for the N KLL peak at $375 \mathrm{eV}$, and $1350-1450 \mathrm{eV}$ for $\mathrm{Al} \mathrm{KL_{23 }} \mathrm{L}_{23}$ peak at $1390 \mathrm{eV}$. The intensity of the both peaks has been determined by measuring peak heights with respect to the background level/15/. The peak to background ratios $(P / B)$ of the N KLL Auger transition measured on 
the synthesized $\mathrm{Al}_{x} \mathrm{~N}_{\mathrm{y}}$ and on the standard $\mathrm{Si}_{3} \mathrm{~N}_{4}$ film (Philipps Eindoven) were compared. Identical comparaison is made with (P/B) of $A \mathrm{KL}_{23} \mathrm{~L}_{23}$ transition in $\mathrm{Al}_{\mathbf{x}} \mathrm{N}_{\mathbf{y}}$ films and in pure Aluminium.

Table 3 : Molecular concentrations in the $\mathrm{Al}_{\mathbf{x}} \mathrm{N}_{\mathrm{y}}$ films.

\begin{tabular}{|c|c|c|c|c|c|c|}
\hline Samples & $(\mathbf{P} / \mathbf{B}$ & $\begin{array}{l}(\mathrm{P} / \mathrm{B}) \text { AlKLL } \\
.02)\end{array}$ & d & $\begin{array}{l}\mathrm{C}_{\mathrm{N}} \\
\left(\mathrm{mol} / \mathrm{cm}^{3}\right)\end{array}$ & $\mathrm{C}_{\mathrm{Al}}$ & $\overline{C_{N} / C_{A l}}$ \\
\hline \multicolumn{7}{|l|}{ references: } \\
\hline $\mathrm{Si}_{3} \mathrm{~N}_{4}$ & 0.5 & - & 3.12 & 0.089 & - & - \\
\hline Al pur & - & 0.32 & 2.698 & - & 0.1 & \\
\hline \multicolumn{7}{|c|}{ experiments : } \\
\hline $35 \mathrm{kHz}$ & 0.43 & 0.24 & & 0.077 & 0.075 & 1.03 \\
\hline $110 \mathrm{kHz}$ & 0.45 & 0.21 & & 0.080 & 0.067 & 1.19 \\
\hline $440 \mathrm{kHz}$ & 0.45 & 0.25 & 3.26 & 0.080 & 0.078 & 1.03 \\
\hline $13.56 \mathrm{MHz}$ & 0.47 & 0.26 & & 0.084 & 0.081 & 1.04 \\
\hline
\end{tabular}

In the following calculations, theoretical compound densities were considered without taking into account the small percentage of Carbon.

We can conclude that the values of $\mathrm{Al}$ and $\mathrm{N}$ molecular concentrations calculated using peak to background ratios for $\mathrm{Al}_{\mathbf{x}} \mathrm{N}_{\mathrm{y}}$ have presumably a composition which is similar to $\mathrm{AlN}$.

\section{$4-$ CONCLUSION :}

Table 4 : Influence of growing temperatures and frequency on AlN coating crystallinity.

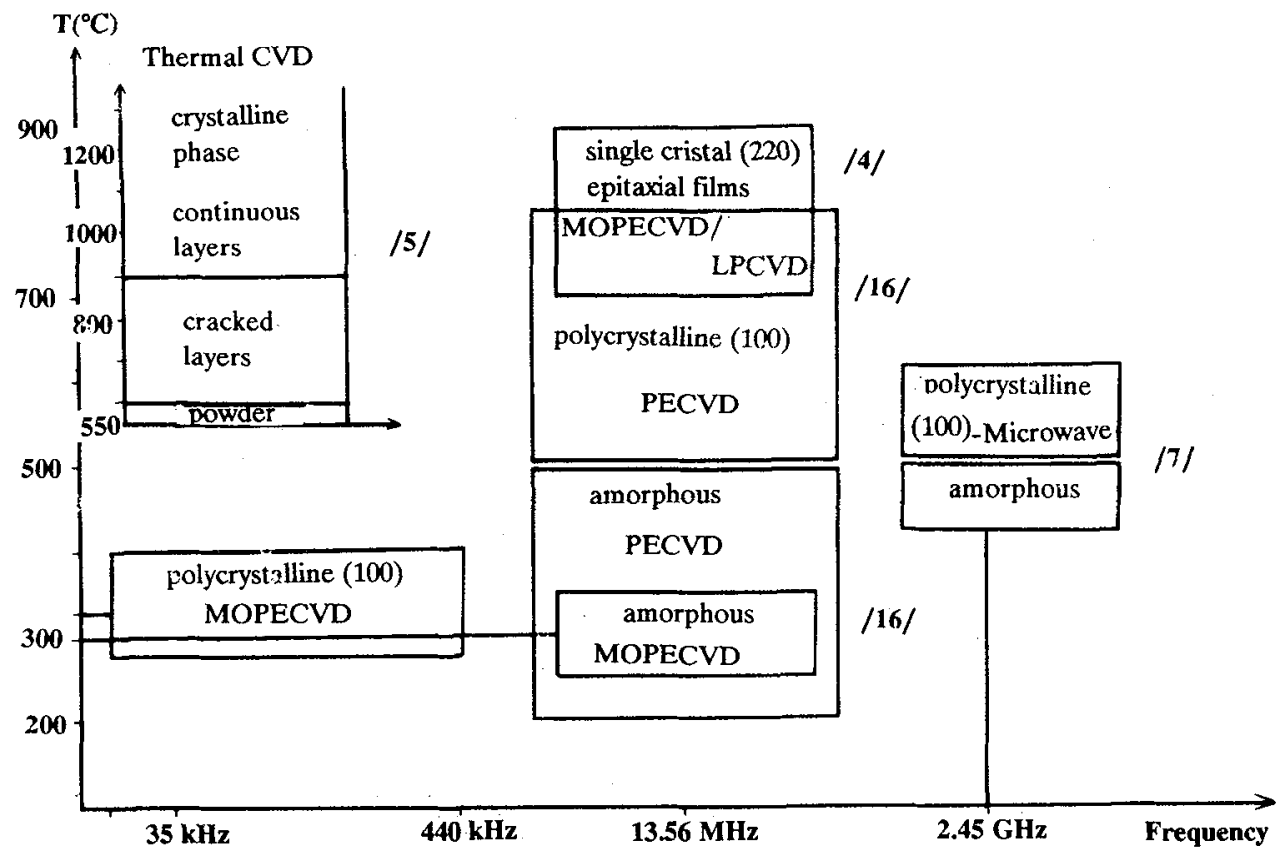


We summarize in table 4, the AlN structure of thin layers obtained in various CVD methods. At high frequencies and low temperature, AIN is always amorphous whereas low frequencies lead to crystalline AlN. The crystalline orientation is strongly dependent on the temperature deposition.

In our conditions, we observed that the particules size of AlN (10î) coatings (the deposition rate too) decrease when the frequency values increase. Furthermore, it has been shown that the substrate has no effect on the crystalline orientation. Above a frequency value of about $13.56 \mathrm{MHz}$, AlN thin films are amorphous. AES studies show that all the samples have a composition which is similar to AlN.

\section{-REFERENCES :}

/1/ FEIL M., Hybrid Circuits, 18 (1989) 29.

/2/ YIM W.M., STOFKO E.J., ZANZUCCHI P.J., PANKOVE J.I., ETTENBERG M. \& GILBERT S.L., J. Appl. Phys., 44(1) (1973) 292.

/3/ DOBRYNIN A.V., NAIDA G.A. \& NOVOSELOV V.A., Phys. Stat. Sol., 104 (1987) K47.

/4/ SATO K., Ultrasonics Symp. Proc. (IEEE, New York), (1985) 192.

/5/ SUZUKI M. \& TANJ H., Proceedings Tenth International Conf. on C.V.D. (1987) 1089.

16/ HASEGAWA F., TAKAHASHI T., KUBO K. \& NANNICHI Y., Japanese Journal of Applied Physics, 26(9) (1987) 1555.

/7/ SOMENO Y., SASAKI M. \& HIRAI T., ibid, 29(2) (1990) L358.

/8/ AZEMA N., DURAND J., BERJOAN R., DUPUY C. \& COT L., Journal of European Ceramic Society, to be published.

/9/ SMIT M.K. \& VERHOOF J.W., Thin Solid Films, 189 (1990) 193.

/10/ PASTRNAK J. \& ROSKOVCOVA L., Phys. Status Solidi, 14 (1966) K5.

/11/ CATHERINE Y., Croissance de couches minces sous flux d'ions. In Journées d'études : Interaction plasmas froids matériaux ,Edition de physique, Oleron(1987), 319.

/12/ ANTHONY R.W., Solid State Chemistry and its Applications, ed. John Wiley and Sons, (1984) 174.

/13/ MATSUDA A., KUMAGI K. \& TANAKA K., Symp. on ISIAT'83, Kyoto, Japan (1983).

/14/ EBERHART J.P., Analyse Structurale et Chimique des Matériaux, ed. Dunod (1989).

/15/ LANGERON J.P., MINEL L., VIGNES J.L., BOUQUET S., PELLERIN F., LORANG G.,

AILLOUD P. \& LE HERICY J., Solid State Communications, 49(5) (1984) 405.

/16/ ITOH H., KATO M. \& SOGIYAMA K., Thin Solid Films, 146 (1987) 255. 